\title{
Maternal Diabetes Does Not Alter Postnatal Development of the Hepatic Glucagon Receptor- Adenylate Cyclase System in the Rat
}

\author{
MARK A. SPERLING, ${ }^{(26)}$ SUPRIYA GANGULI, RON CHRISTENSEN, AND SANDRA VOINA \\ Department of Pediatrics, Division of Endocrinology, Children's Hospital Medical Center, University of Cincinnati, \\ Cincinnati, Ohio, USA
}

\begin{abstract}
Summary
We examined the postnatal maturation of the glucagon receptor-adenylate cyclase system of liver plasma membrane from rats born to normal or streptozotocin-induced diabetic mothers and compared results to those of nonpregnant adult. Diabetes in mothers was confirmed by hyperglycemia $(458 \pm 41$ versus $128 \pm$ $13 \mathrm{mg} / \mathrm{dl}$; mean \pm S.E. $)$ and relative hypoinsulinemia $(4.3 \pm 1.0$ versus $7.4 \pm 1.0 \mathrm{ng} / \mathrm{ml}$ ) when compared to controls. Pups born to diabetic mothers (IDM) were hyperglycemic $(59 \pm 6$ versus $23 \pm$ $5 \mathrm{mg} / \mathrm{dl})$ but not significantly hyperinsulinemic $(4.3 \pm 0.5$ versus $3.5 \pm 0.6 \mathrm{ng} / \mathrm{ml}$ ) when compared to control pups on day 1 ; by day 7 and on day 21 glucose and insulin were similar in IDM and control pups. Binding of $\left[{ }^{125} I\right]$-glucagon to liver plasma membrane was markedly reduced in both IDM and control newborns corresponding to 20,25 , and $30 \%$ of normal adult values on days 1,7 , and 21 of life. Resolution of the curvilinear Scatchard plots of binding data by the two-site model (high affinity-low capacity; low affinity-high capacity) revealed a progressive increase in receptor number $\left(\times 10^{11} / \mathrm{mg}\right.$ protein) of the high affinity sites from 0.9 on day 1 to 1.7 on day 7 and 2.2 on day 21 ; normal adult was 6.1. Neither the affinity constants of the high or low affinity components, nor the number of low affinity sites differed substantially between adult or newborns at any postnatal age. Basal cAMP production (pM/mg protein/10 min) was similar in adult and newborn. But cAMP production in response to $10^{-9}$ to $10^{-6} \mathrm{M}$ glucagon was always greater in adult than newborn until day 21. Whereas adult liver plasma membrane increased cAMP production with $10^{-9} \mathrm{M}$ glucagon, the minimum concentration of glucagon capable of consistently and significantly increasing cAMP in newborn on day 1 and 7 was $10^{-7} \mathrm{M}$. cAMP production above basal in response to glucagon correlated with glucagon binding and with the number of high affinity glucagon receptors. Adequacy of neonatal liver adenylate cyclase activity was demonstrated by the equivalent responses in CAMP in adult or newborn at any ages after stimulation with $15 \mathrm{mM}$ sodium fluoride; thus, the reduction in number of glucagon receptors in the newborn was specifically responsible for decreased $\mathrm{cAMP}$ production after glucagon stimulation. No difference in this pattern of postnatal maturation of glucagon receptors-cAMP production was apparent in liver plasma membrane from controls or IDM pups.
\end{abstract}

\section{Abbreviations}

$B / F$, bound to free ratio

$\mathrm{BSA}$, bovine serum albumin

IDM, diabetic mothers

RIA, radioimmunoassay

The fetal and postnatal development of hepatic insulin and glucagon receptors proceeds in opposite directions. Close to term and in the immediate newborn period, the number and/or affinity of hepatic insulin receptors are higher than in adult tissue; gradual reduction to adult values occurs as the animal matures $(6,8,9,13$, 19). In contrast, the number of hepatic glucagon receptors and their ability to produce cAMP in response to glucagon is low in the fetus or newborn and gradually increases to adult values as the animal matures $(2,5,24)$. Human or experimental maternal diabetes, if poorly controlled, results in fetal hyperinsulinemia and a paradoxical increase, rather than the expected down-regulated decrease; of insulin receptors $(12,14)$. The influence of maternal diabetes on the development of hepatic glucagon receptors has not been examined. In this study, we examine the potential influence of experimentally induced maternal diabetes on the developmental characteristics of the hepatic glucagon receptor-adenylate cyclase system in newborn rat pups.

\section{MATERIALS AND METHODS}

Animals. Diabetes was induced in mature virgin rats by injecting freshly dissolved streptozotocin, $45 \mathrm{mg} / \mathrm{kg}$ into the tail vein. A control group received saline only $(10,16)$. One to two days later, control $(N=13)$ and glycosuric $(N=11)$ animals were mated and pregnancy confirmed by the presence of a vaginal plug and by subsequent palpation. All animals were housed in individual cages and had free access to rat chow and water with no attempt at controlling maternal diabetes by insulin. The existence of diabetes was checked daily by examining for glucosuria and at term by measurements of fetal and maternal blood glucose and serum insulin. All animals delivered spontaneously. Within $12 \mathrm{~h}$ of delivery (day 1) the entire litter of five control and four diabetic mothers were removed, weighed, livers quickly excised and pooled for immediate processing and preparation of liver plasma membranes. In further groups of pups born to control or diabetic mothers, newborn rats were allowed to develop through 7 or 21 days before sacrifice, collection of blood for measurements of glucose and insulin and preparation of plasma membranes from pooled livers. Until sacrifice, litters born to controls were allowed to nurse with their own mothers. Because preliminary experiments had shown that untreated diabetic mothers nursed poorly, resulting in diminished weight gain of their newborn pups, litters born to diabetics were "fostered" with healthy control mothers whose own litters had been removed. To compare results of glucagon receptors and cAMP production with adult values, liver plasma membranes were also prepared from three healthy nonpregnant adult rats.

Liver plasma membranes. Partially purified (step 11) liver plasma membranes were prepared by the method of Neville et al. as previously described from this laboratory (20). In order to perform a complete dose-response curve of glucagon binding and glucagon-stimulated cAMP generation, as well as the cAMP response to sodium fluoride, it was necessary to pool livers from all litters at a given time point to yield a sufficient quantity of membrane. Protein concentration of these plasma membranes was 
determined by the method of Lowry et al. (11) using bovine serum albumin as standard.

Binding studies. Monoiodinated $\left[{ }^{125} \mathrm{I}\right]$-glucagon was prepared by the method of Jorgensen and Larsen (7). Purified crystalline glucagon, a gift of Eli Lilly and Copany, Indianapolis, IN, was used for iodination and displacement. Binding studies were performed in polyethylene tubes as previously described (20). To each tube were added $100 \mu \mathrm{l} \mathrm{3 \%} \mathrm{BSA} \mathrm{in} \mathrm{Tris} \mathrm{buffer} \mathrm{pH} \mathrm{7.6,} 50 \mu \mathrm{l}$ standard or buffer, $100 \mu \mathrm{l}$ buffered hormone $(20,000 \mathrm{cpm}$; approximately $10 \mathrm{pg}$ ), and $50 \mu \mathrm{l}$ of membrane preparation diluted in Tris buffer to contain $50 \mu \mathrm{g}$ of protein. Incubation was carried out for $16 \mathrm{~h}$ at $4^{\circ} \mathrm{C}$ in the absence or presence of unlabeled glucagon at $0.125-100 \mathrm{ng} / \mathrm{tube}$. Separation of bound from free was achieved by centrifugation at $4^{\circ} \mathrm{C}$ for $4 \mathrm{~min}$ and aspiration of the supernatant, followed by counting of the pellet in a gamma counter. Nonspecific binding was defined as residual radioactivity in the presence of $100 \mathrm{ng}$ glucagon and subtracted from each point to yield specific binding per $50 \mu \mathrm{g}$ of liver membrane protein. Each point in the displacement curve, including total counts and nonspecific binding, was determined in triplicate using the mean to construct the displacement curve. Binding data were converted to Scatchard plots and resolved according to the two-site model into high and low-affinity sites using Rosenthal's correction (17). The number of sites for both classes of receptors, expressed per mg of protein of liver plasma membrane, was calculated from the $x$ intercept of the Scatchard plot by use of Avogadro's number.

cAMP generation. cAMP generation was performed at $30^{\circ} \mathrm{C}$ in a total volume of $250 \mu \mathrm{l}$ with $50 \mu \mathrm{g}$ membrane protein and an ATP generating medium based on the method of Rosselin and Freychet (18), as previously described in detail from this laboratory (20). Measurement of cAMP generated in the presence of $10^{-9}$ to $10^{-6} \mathrm{M}$ glucagon was used as an index of specific responsiveness and its relation to the glucagon receptor; as an index of nonspecific stimulation, sodium fluoride was used at a final concentration of $15 \mathrm{mM}$ in one set of tubes containing the generating medium but no glucagon. Blank tubes contained no membrane or hormone and these values were subtracted from all other values. Each point of the dose-response curve including blanks, membrane only, and sodium fluoride was generated in duplicate and each duplicate point was run in triplicate in a radioimmunoassay for cAMP using the method and an antibody kindly provided by Dr. Alton Steiner $(20,21)$; thus, reported values at each point are the mean of six determinations. The absolute sensitivity of this method is $0.1 \mathrm{pM} /$ tube. The intraassay coefficient of variation is $5 \%$ and the interassay coefficient of variation is $12 \%$.

Substrate and hormones. Glucose was measured by a glucose oxidase method using the Yellow Springs Instrument glucose analyser. Insulin was measured by a specific rat RIA using the Novo kit (15).

Statistical comparison. Where individual measurements were made, data are presented as mean \pm S.E. and statistical comparisons performed by Student's paired or unpaired $t$ test. Linear regression analysis was used to assess the correlation between initial binding or high affinity sites and cAMP production in response to glucagon.

\section{RESULTS}

Table 1 lists the characteristics of animals studied. Maternal diabetes was severe as reflected in a blood glucose at term of 458 $\pm 41 \mathrm{mg} / \mathrm{dl}$ compared to $128 \pm 13 \mathrm{mg} / \mathrm{dl}$ in controls $(P<0.05)$. Similarly, serum insulin was lower in diabetic mothers $(4.3 \pm 1$ $\mathrm{ng} / \mathrm{ml})$ than in controls $(7.4 \pm 1.8 \mathrm{ng} / \mathrm{ml})$. Maternal diabetes did not influence the number of animals born per litter but birth weight and pooled liver weight were lower; serum glucose was significantly higher and mean insulin was higher in the pups born to diabetic mothers (IDM) than those born to control mothers. At age 7 days, total body weight was still lower in the IDM. Other indices were equivalent by 21 days in control and IDM animals.

Scatchard plots of glucagon binding data in the control and diabetic rats are presented respectively in Figures 1 and 2. Scatchard plots from three adult rat livers are shown in each for comparison. It is apparent that the bound to free ratio $(B / F)$ and receptor number $\left(\mathrm{M} /\right.$ liter $\left.\times 10^{-11}\right)$ in the newborn rats were markedly lower than those of adult and although $\mathrm{B} / \mathrm{F}$ and total receptor number increased with maturation, values at 21 days were still substantially below those of adult. Resolution of these curvilinear Scatchard plots into their high and low affinity components provides a clearer separation of the differences between the pups born to normal or diabetic mothers and normal adult controls (Table 2). The diminished glucagon binding in the newborns at all ages examined was not due to major differences in the affinity constants of the high- or low-affinity sites, which were similar at all ages. Although the affinity constant of the lowaffinity sites on day 1 appeared to be lower in the diabetic offspring, the average of day 1 and day 7 in IDM was similar to the combined day 1 and day 7 of control pups. The major factor responsible for the difference in binding was clearly the absolute number of high affinity sites: receptor sites per mg protein on day 1 and day 7 were only $20-25 \%$ those of adult and even on day 21 these receptor sites constituted only $30-35 \%$ of adult high-affinity site number. In contrast, the number of low-affinity sites was $50-75 \%$ of adult values on day 1 and 7 and almost equivalent on day 21 . No major differences were apparent between newborns of normal or diabetic mothers.

cAMP responsiveness is shown in Table 3. Basal cAMP values (pmoles per $\mathrm{mg}$ protein/10 min) were similar at all ages both in the control pups and in the pups born to diabetic mothers. Similarly, sodium fluoride-stimulated cAMP values were similar at all ages, indicating the presence of a functional adenylate cyclase system that could be maximally stimulated; however, the cAMP response to glucagon stimulation clearly differed between adult and newborn. Adult liver membranes responded by a significant increment in cAMP production above basal to glucagon

Table 1. Characteristics of animals studied

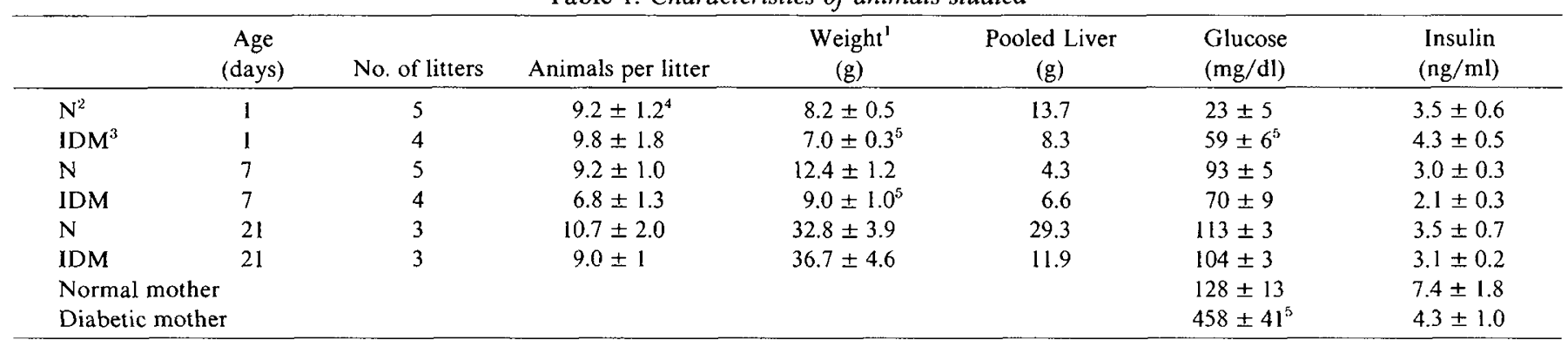

\footnotetext{
${ }^{1}$ Per animal.

${ }^{2} \mathrm{~N}$, pups born to normal mother.

${ }^{3}$ IDM, pups born to diabetic mother.

${ }^{4}$ Values are mean \pm S.E.

${ }^{5} P<0.05$ compared with normal control.
} 

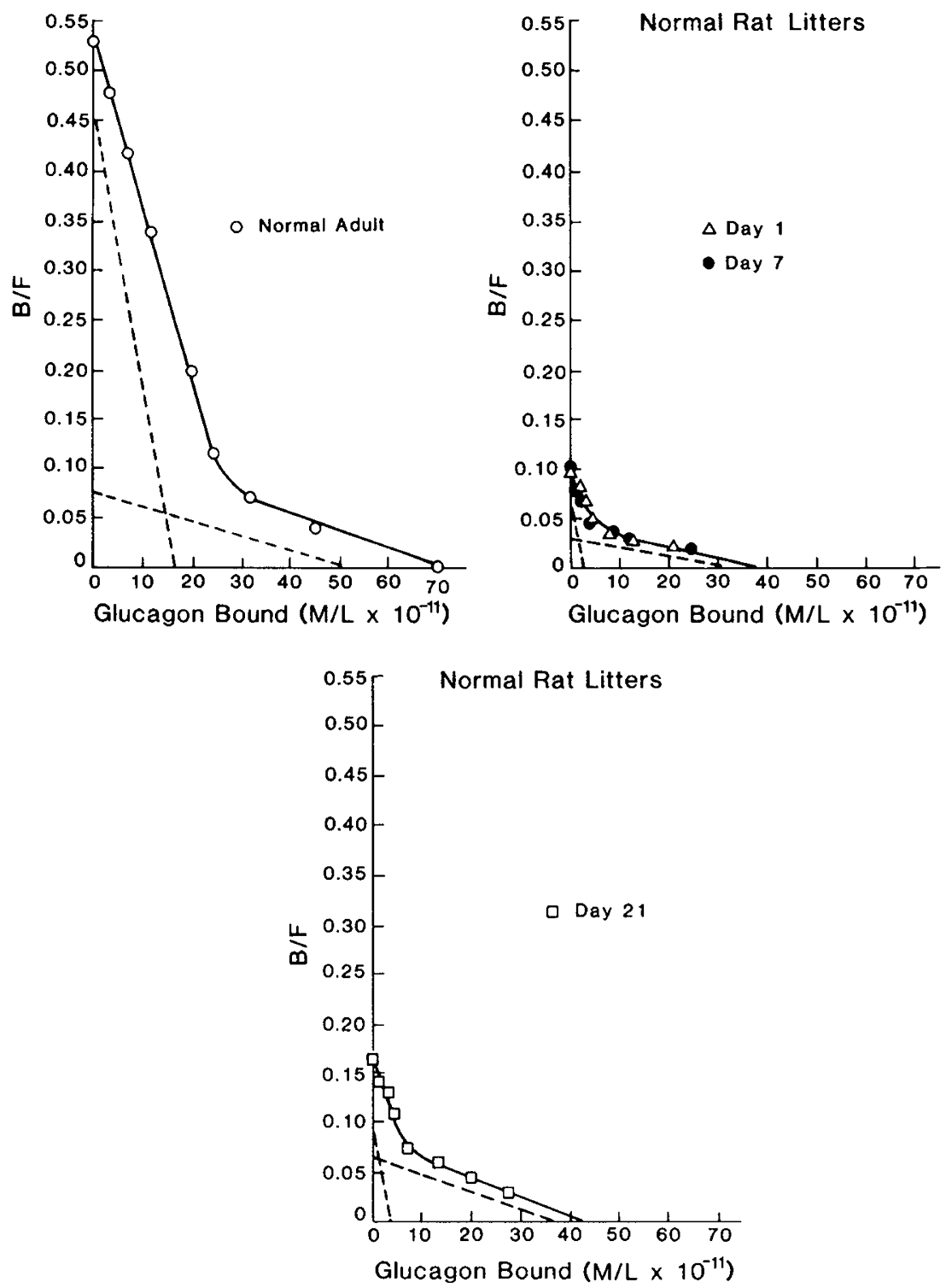

Fig. 1. Scatchard plots of glucagon binding data in liver plasma membranes from rats born to normal mothers and from healthy adult controls. The curvilinear plots have been resolved according to the two-site model into high affinity-low capacity and low affinity-high capacity components. Data from animals aged 1 and 7 days have been combined because the plots are indistinguishable. Note the reduction in glucagon bound in newborns relative to adult. See text and Table 2 for details.

$10^{-9} \mathrm{M}$ with a progressively greater increment of cAMP production to increasing glucagon concentrations. In contrast, glucagon at $10^{-9} \mathrm{M}$ failed to increase cAMP in all newborns even on day 21. Glucagon at $10^{-8} \mathrm{M}$ elicited some response in controls on day 21 and in the diabetic litters on day 1 and day 7 as well. Consistent increments in cAMP were not seen in all newborns until a glucagon concentration of $10^{-7} \mathrm{M}$ was used. The cAMP response to any dose of glucagon was significantly lower in the newborns on day 1 and day 7 than in adults. By day 21, cAMP responses to glucagon were not significantly different from adult. The amount of cAMP produced above basal in response to any dose of glucagon correlated significantly with initial glucagon binding and with the proportion of the total receptor population that were occupied by glucagon.

\section{DISCUSSION}

In this study we examined the potential influence of maternal diabetes on the postnatal development of the hepatic glucagon receptor-adenylate cyclase system in rats. The results in pups born to control healthy mothers demonstrate a functional immaturity in glucagon receptor number, which increases progressively with maturation although values at $2 \mathrm{l}$ days are still lower than those of mature adult. Affinity constants of either receptor class did not vary during maturation. The functional significance of these maturational changes, involving mainly high affinity sites, is evident from the relationship between glucagon binding or number of high affinity sites and the amount of cAMP produced in response to any dose of glucagon.

That the relationship of the cAMP response to glucagon and glucagon receptors was specific and not merely a reflection of immaturity in the adenylate cyclase system, was shown by the comparable increase in cAMP in adult and newborns at all ages examined when stimulated with sodium fluoride. These results are in high agreement with those reported by Vinicor et al. (24) and Blazquez et al. (2) who also examined the developmental pattern of glucagon binding and its relationship to glucagon-stimulated cAMP production in partially purified membranes from normal developing rat liver. But these authors only measured the binding of tracer glucagon and did not provide complete displacement curves with unlabeled glucagon, thereby precluding assessment of the number or affinity of receptors via Scatchard analysis. The 

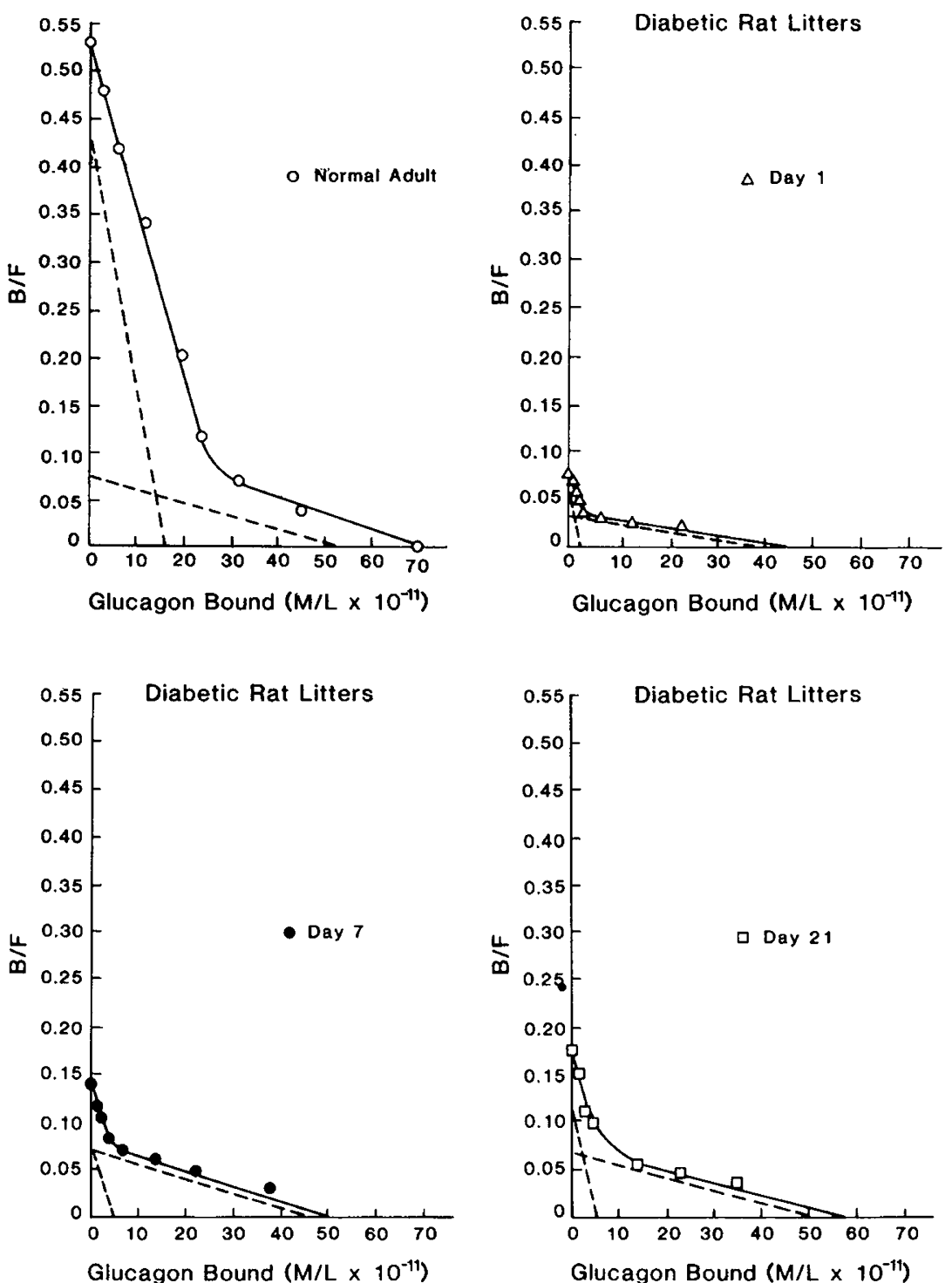

Fig. 2. Scatchard plots of glucagon binding data in liver plasma membranes from rats born to streptozotocin-induced diabetic mothers and from normal adults. The curvilinear plots have been resolved according to the two-site model. Note the progressive increase in glucagon binding with increasing postnatal age. See text and Table 2 for details.

Table 2. Glucagon binding, receptor number and characteristics in liver plasma membranes from normal adult rat and pups born to control and diabetic rats

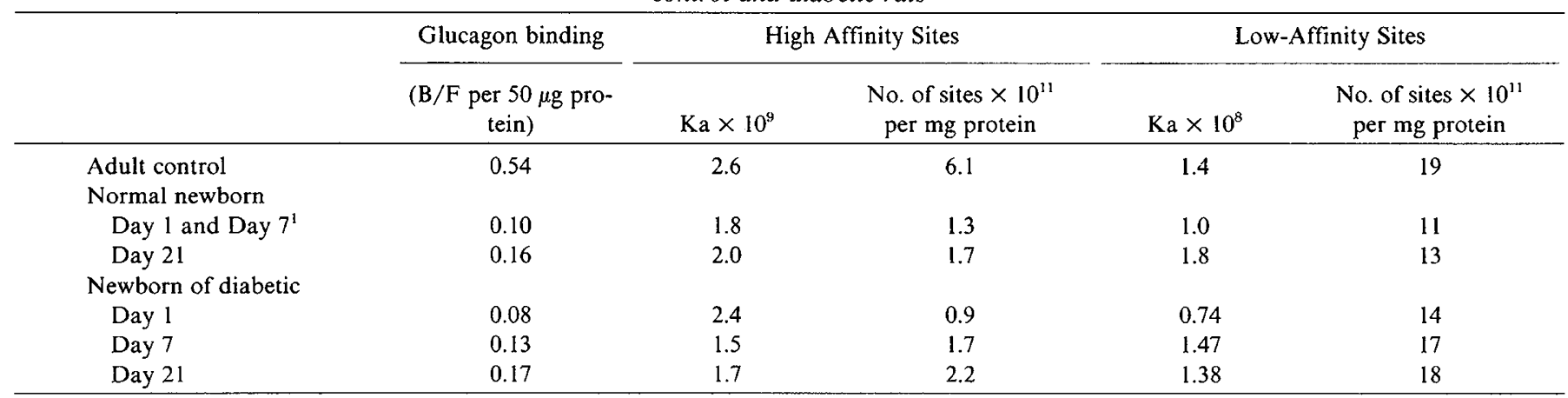

${ }^{1}$ Data from day 1 and 7 have been combined because Scatchard plots were indistinguishable (see Fig. 1).

curvilinear Scatchard plots obtained in our studies permit such resolution and indicate that increasing high affinity sites reflect greater maturational changes. A better correlation existed between high affinity sites and initial glucagon binding or with glucagonstimulated cAMP production, but occupancy of these high affinity sites does not strictly correlate with cAMP production. Hence, some other maturational change in the capacity to stimulate cAMP must be occurring in parallel.

The curvilinear Scatchard plots are also compatible with the negative cooperativity model of DeMeyts et al. (3). We did not 
Table 3. Glucagon-stimulated cAMP production in liver plasma membranes from newborn rats (pmoles per $\mathrm{mg}$ protein/l0 min)

\begin{tabular}{|c|c|c|c|c|c|c|}
\hline & Basal & \multicolumn{4}{|c|}{ Glucagon dose (M/liter) } & $\begin{array}{c}\text { Sodium fluoride } \\
\text { (15 mM) }\end{array}$ \\
\hline Adult control & $303 \pm 59^{\prime}$ & & & & & \\
\hline Increment above basal & & $163 \pm 72^{2}$ & $309 \pm 58^{3}$ & $429 \pm 92^{3}$ & $546 \pm 110^{3}$ & $2261 \pm 181^{3}$ \\
\hline \multicolumn{7}{|l|}{ Normal rat litter } \\
\hline Day 7 & $338 \pm 17$ & & & & & \\
\hline Increment above basal & & $6 \pm 22$ & $72 \pm 38^{4}$ & $173 \pm 18^{3,4}$ & $218 \pm 34^{3,4}$ & $1325 \pm 119^{3}$ \\
\hline Day 21 & $360 \pm 23$ & & & & & \\
\hline Increment above basal & & $36 \pm 29$ & $126 \pm 25^{3,4}$ & $222 \pm 18^{3}$ & $284 \pm 27^{3.4}$ & $2390 \pm 91^{3}$ \\
\hline \multicolumn{7}{|l|}{ Diabetic rat litter } \\
\hline Day 7 & $469 \pm 22$ & & & & & \\
\hline Increment above basal & & $42 \pm 37$ & $116 \pm 14^{3,4}$ & $160 \pm 32^{3.4}$ & $240 \pm 31^{3,4}$ & $3448 \pm 167^{3}$ \\
\hline Day 21 & $349 \pm 45$ & & & & & \\
\hline Increment above basal & & $37 \pm 19$ & $195 \pm 28^{3}$ & $383 \pm 26^{3}$ & $443 \pm 65^{3}$ & $2318 \pm 124^{3}$ \\
\hline
\end{tabular}

plot our data according to average affinity profiles, however, because there were no major differences in affinities of either receptor class between newborns of various ages and adult; thus, average affinity profiles would be similar. Irrespective of whether the two-site or negative cooperativity model is used, the general characteristics of the glucagon receptor of newborn rat liver membranes are similar to adult, even on day 1 of life.

The differences between adult and newborns can also not be attributed to differences in membrane purity, differences in enzymatic degradation of glucagon or significant contamination with hemopoeitic tissue. We have previously shown that liver plasma membranes prepared by the method used in the present study are optimal in terms of binding of labeled glucagon or insulin, and display less degradation of hormone than membranes prepared by other methods $(4,22)$. In addition, in agreement with other investigator's findings $(13,24)$, the degree of enrichment in markers of membrane purity such as $5^{\prime}$ nucleotidase, glucose-6phosphatase, or maximal cAMP response to sodium fluoride is similar in adults and fetal/newborn liver membranes prepared by this method (22). Finally, degradation of hormone is lower by membranes of newborns than of adult (24).

Diabetes in the mother did not significantly alter the postnatal maturation of the glucagon receptor-adenylate cyclase system in our model. It should be noted, however, that pups born to these diabetic rats did not manifest the macrosomia and hyperinsulinemia typical of human diabetes $(12,14)$. Rather, although blood glucose at birth was clearly higher, body and liver weights were lower at birth in diabetic offpring than in control newborns. This phenomenon has previously been described in the offspring of streptozotocin-induced diabetic rats: severe maternal diabetes (blood glucose $>300 \mathrm{mg} / \mathrm{dl}$ ) results in offspring with reduced body weight and without hyperinsulinemia, whereas mild maternal diabetes (blood glucose $100-200 \mathrm{mg} / \mathrm{dl}$ ) results in hyperinsulinemia and a modest increase in body weight $(10,16)$. By these criteria, our animals had severe diabetes: in the absence of insulin treatment they fed poorly and gained less weight, their offspring were smaller and had normal or perhaps only marginally increased insulin in comparison to newborn control pups. In addition, although the CAMP response to glucagon per unit mass of liver membrane was similar in both groups, the weight of liver on day 1 appeared to be lower in offspring of diabetics than in controls. Hence, the total cAMP response and possibly total glycogenolysis may be less in offspring of diabetics than in controls on day one of life. These factors, in association with poor feeding and hence the need to foster the diabetic litters with nondiabetic mothers, probably accounts for the tendency to lower blood glucose on day 7 of life. The absence of evidence for a significant influence of maternal diabetes on the postnatal maturation of the glucagon receptor-adenylate cyclase system in this rat model does not preclude the possibility of a significant influence of insulin-dependent or gestational diabetes in other models such as the human. In the human, hyperinsulinemia as well as excessive nutrient transfer results in macrosomia; these factors may combine to significantly alter the in utero and postnatal maturation of the glucagon receptor complex.

Although the physiological significance of the remarkably different maturational patterns in insulin and glucagon receptors remains to be determined, the available data in animals suggest the following hypothesis. In utero, the increased concentration of insulin receptors $(6,8,9,13,19)$ while glucagon receptors and glucagon-stimulated cAMP production are diminished $(2,5,24)$, would favor anabolic processes such as glycogen synthesis, whereas catabolic processes such as glycogenolysis would be limited. Hepatic glycogen stores increase dramatically toward term (1) in line with the increase in insulin receptors. Failure to down regulate insulin receptors by hyperinsulinemia might be expected to exaggerate these anabolic processes, as indeed occurs in hyperinsulinemic infants born to diabetic mothers (12). In newborn animals, the decline in insulin receptors and maturation of functional glucagon receptors would more readily permit mobilization of glycogen stores during fasting when glucagon secretion increases, whereas insulin secretion decreases (23). In our rat model, the absence of acceleration in glucagon receptor maturation postnatally might be considered an additional factor predisposing to hypoglycemia. Because our rat model is clearly different from diabetes in human pregnancy, particularly with respect to fetal 
hyperinsulinemia, the possibility that maturation of the glucagon receptor complex is modified by diabetes in human pregnancy cannot be excluded.

\section{REFERENCES AND NOTES}

1. Battaglia, F. C.: Commonality and diversity in fetal development: Bridging the interspecies gap. Pediatr. Res., 12: 736 (1978).

2. Blazquez, E., Rubalcava, B., Montesano, R., Orci, L., and Unger, R. H.: Development of insulin and glucagon binding and the adenylate cyclase response in liver membranes of the prenatal, postnatal and adult rat: Evidence of glucagon "resistance." Endocrinology, 98: 1014 (1976).

3. DeMeyts, P. and Roth, J.: Cooperativity in ligand binding: A new graphic analysis. Biochem. Biophys. Res. Commun., 66: 1118 (1975).

4. Ganguli, S., Voina, S., and Sperling, M.: Influence of liver plasma membrane preparation on glucagon and insulin binding, degradation and cAMP generation: a comparison of three methods. Program of the 61st Annual Meeting of the Endocrine Society 1979, p. 172 (Abst 339).

5. Ganguli, S., Whitsett, J., Voina, S., Velayo, N., and Sperling, M. A.: A difference between fetal and hepatic glucagon receptors coupled to adenylate cyclase: evidence for postnatal appearance of a new population of glucagon receptors. Program of the 62nd Annual Meeting of the Endocrine Society, 1980, p. 113 (Abst 155).

6. Herzberg, V. L., Boughter, M. J., Carlisle, S. K., Ahmad, F., and Hill, D. E.: ${ }^{125} \mathrm{I}-$ insulin receptor binding to cord blood erythrocytes of varying gestational age and comparison with adult values. Pediatr. Res., 14: 4 (1980).

7. Jorgensen, K. H. and Larsen, U. D.: Purification of ${ }^{125} \mathrm{I}$-glucagon by anion exchange chromatography. Horm. Metab. Res., 4: 223 (1972).

8. Kaplan, S. A.: The insulin receptor. Pediatr. Res., 15: 1156 (1981)

9. Kappy, M. S. and Plotnick, L.: Studies of insulin binding in children using human erythrocytes in small amounts of blood. Diabetes, 28: 1001 (1979).

10. Kervran, A., Guillame, M., and Jost, A.: The endocrine pancreas of the fetus from diabetic pregnant rat. Diabetologia, 15: 387 (1978).

11. Lowry, O. H., Rosebrough, N. J., Farr, A. L., and Randall, R. J.: Protein measurement with the Folin reagent. J. Biol. Chem., 193: 265 (195I).

12. Neufeld, N. D., Kaplan, S. A., Lippe, B. M., and Scott, M.: Increased monocyte insulin receptors binding of ${ }^{12.5} \mathrm{I}$-insulin in infants of gestational diabetic mothers. J. Clin. Endocrinol. Metab., 47: 590 (1978).
13. Neufeld, N. D., Scott, M., and Kaplan, S. A.: Ontogeny of the mammalian insulin receptor: Studies of human and rat fetal liver membranes. Devel. Biol. 78: 151 (1980).

14. Neufeld, N. D., Kaplan, S. A., and Lippe, B. M.: Monocyte insulin receptors in infants of strictly controlled diabetic mothers. J. Clin. Endocrinol. Metab., 52: 473 (1981).

15. Novo Laboratories, Denmark: Radioimmunoassay kit for rat insulin.

16. Pitkin, R. M. and Van Orden, D. E.: Fetal effects of maternal streptozotocindiabetes. Endocrinology, 94: 1247 (1974).

17. Rosenthal, H. E.: A graphic method for determination and presentation of binding parameters in a complex system. Anal. Biochem., 20: 252 (1967).

18. Rosselin, G. and Freychet, P.: Basal and hormone-stimulated adenylate cyclase in liver plasma membranes: Measurement by radioimmunoassay of cyclic AMP. Biochim. Biophys. Acta, 304: 541 (1973).

19. Sinha, M. K., Ganguli, S., and Sperling, M. A.: Disappearance of erythrocyte insulin receptors during maturation in sheep. Diabetes, 30: 311 (1981).

20. Sperling, M. A., Ganguli, S., Voina, S., Kaptein, E., and Nicoloff, J. T.: Modulation by thyroid status of the glucagon receptor-adenyl cyclase system in rat liver plasma membranes. Endocrinology, 107: 684 (1980)

21. Steiner, A. L., Kipnis, D. M., Utiger, R., and Parker, C.: Radioimmunoassay for the measurement of adenosine $3^{\prime}, 5^{\prime}$-cyclic phosphate. Proc. Nat1. Acad. Sci. USA, 64: 367 (1973).

22. Sterman, B. M., Ganguli, S., Devaskar, S., and Sperling, M. A.: Hypothyroidism and glucocorticoids modulate the development of hepatic insulin receptors. Pediatr. Res. (In press).

23. Unger, R. H., Dobbs, R. E., and Orci, L.: Insulin, glucagon, and somatostatin secretion in the regulation of metabolism. Ann. Rev. Physiol., 40: 307 (1978).

24. Vinicor, F., Higdon, G., Clark, J. F., and Clark, C. M., Jr.: Development of glucagon sensitivity in neonatal rat liver. J. Clin. Invest., 58: 571 (1976).

25. Portions of this paper were presented at the Society for Pediatric Research meeting, Washington, D.C. April, 1979.

26. Requests for reprints should be addressed to: Dr. Mark A. Sperling, Professor of Pediatrics, Children's Hospital Medical Center, University of Cincinnati, E1land and Bethesda Avenues, Cincinnati, Ohio 54229.

27. This research was supported by grants from the USPHS HD 12613, HD 11725 and by the Juvenile Diabetes Foundation.

28. Received for publication March 25, 1982.

29. Accepted for publication June 15, 1982. 